\title{
ANTIPHOSPHOLIPID AND ANTINEUTROPHIL ANTIBODIES LEVELS IN MEN WITH STABLE CORONARY HEART DISEASE AND POSTINFARCTION CARDIOSCLEROSIS AND ITS RELATIONSHIP WITH THE DISEASE MANIFESTATION
}

D0I: 10.36740/WLek202003111

\author{
Marina S. Nazarova, Mykola A. Stanislavchuk, Liudmyla V. Burdeina, Nataliia V. Zaichko \\ NATIONAL PIROGOV MEMORIAL MEDICAL UNIVERSITY, VINNYTSIA, UKRAINE
}

\begin{abstract}
The aim is to study the levels of antiphospholipid (aPL) and antineutrophil antibodies in men with stable coronary heart disease (CHD) with postinfarction cardiosclerosis and to evaluate its relationship with the disease manifestation.

Materials and methods: 164 men with stable $C H D$ and postinfarction cardiosclerosis (53.0 $\pm 9.14(\mathrm{M} \pm \sigma)$ years) and 48 age-matched men without CHD were examined. The total aPL IgG and IgM, beta-2 glycoprotein 1 antibodies (anti-ß2-GP 1) IgG and IgM, and antibodies for neutrophil proteinase-3 / myeloperoxidase (anti-PR3 / MP0) IgG were determined by ELISA.

Results: Positive levels of aPL and anti- $\beta 2-\mathrm{GP} 1$ of $\mathrm{gG}$ were identified in $56.7 \%$ (33.5\% double positivity of aPL + anti- $-\beta 2-G P 1)$ and $29.2 \%$ of control group ( $p<0.001$ ), while the $\lg \mathrm{M}$ was lower ( $11.6 \%$ vs. $6.2 \%, \mathrm{p}=0.55$, respectively). Significantly higher (1.5-1.7 times) levels of aPL and anti- $\beta 2-\mathrm{GP} 1$ were identified in patients who underwent myocardial infarction (MI) aged less than 44 years, after Q-MI, recurrent $\mathrm{MI}$, in the presence of ischemic stroke, livedo reticularis. In $6.7 \%$ of patients with positive levels of aPL and anti-ß2-GP 1 low lgG anti-PR3 / MPO levels were detected.

Conclusions: In men with postinfarction cardiosclerosis, IgG positivity according to total aPL and anti- $\beta 2-\mathrm{GP} 1$ is associated with a higher incidence of Q-MI and with recurrent MI. Men with postinfarction cardiosclerosis have a tendency to increase anti-PR3 / MPO levels of IgG under conditions of double aPL positivity and anti- $\beta 2-\mathrm{GP1}$ of IgG
\end{abstract}

KEY WORDS: coronary heart disease, antiphospholipid syndrome, antineutrophil antibodies

Wiad Lek. 2020;73(3):466-470

\section{INTRODUCTION}

Antiphospholipid syndrome (APS) as an independent factor of myocardial infarction (MI) and other forms of coronary heart disease (CHD) is attracting increasing attention $[1 ; 2$; $3]$. The prevalence of primary APS is $40-50$ cases per 100,000 population and annually approximately 5 new cases per 100,000 population are detected [4]. Among patients with acute coronary syndrome, the frequency of APS ranges from $6.1 \%$ to $43.3 \%$ [5]. The development of APS is due to the formation of antibodies to the own phospholipids (cardiolipin, phosphatidylserine, phosphatidylinositol), cofactor proteins and their complexes with phospholipids (antibodies to $\beta 2$-glycoprotein 1 (anti- $\beta 2-G P 1)$, annexin, thrombomodulin etc). Antiphospholipid antibodies (aPL) cause immune inflammatory activation of the endothelium, initiate the development of thrombophilia, thrombosis and atherothrombosis of various vessels, including coronary arteries, leading to MI [2]. On the other hand, ischemic-reperfusion lesions of the myocardium can act as a trigger for antigen-dependent aPL synthesis and the development of APS, as cardiolipin, a phospholipid with the most potent immunogenic properties enter the circulatory channel [6]. There is evidence in one of the studies that elevated aPL levels of IgG and IgM were detected in 100\% of patients in the acute period of MI [7].
Another factor influencing inflammatory activation of the coronary artery endothelium may be antibodies to neutrophil proteinase-3 and myeloperoxidase (anti-PR3 / MPO) [8; 9]. Anti-PR3 / MPO cause leukocyte degranulation and endothelial lining of small vessels (arterioles, venules, capillaries) and cause microcirculatory disorders. Microcirculatory disorders significantly impair myocardial status and increase the risk of CHD progression $[10 ; 11]$. It has been recently demonstrated that anti-PR3 / MPOs can be produced concurrently with aPL, which aggravates systemic vasculitis [12]. The question of possible associations of APS components with anti-PR3 / MPO in $\mathrm{CHD}$ patients with postinfarction cardiosclerosis remains open.

\section{THE AIM}

The aim is to study the levels of aPL and antineutrophil antibodies in men with stable CHD with postinfarction cardiosclerosis and to evaluate its relationship with the disease manifestation.

\section{MATERIALS AND METHODS}

An open cross-sectional study was conducted on a case-control basis. 164 patients with stable CHD with 
Table I. Clinical and demographic features of CHD group and control group

\begin{tabular}{cccc}
\hline & Patients with CHD, $\mathbf{n}=\mathbf{1 6 4}$ & Control, $\mathbf{n}=\mathbf{4 8}$ & p value \\
\hline Age, years $(\mathrm{M} \pm \sigma)$ & $53.0 \pm 9.14$ & $52.1 \pm 8.69$ & 0.860 \\
\hline Body mass index, $\mathrm{kg} / \mathrm{m} 2(\mathrm{M} \pm \sigma)$ & $29.9 \pm 3.74$ & $29.2 \pm 2.68$ & 0.141 \\
\hline Body mass index $\geq 30 \mathrm{~kg} / \mathrm{m} 2, \mathrm{n}(\%)$ & $83(50.6 \%)$ & $18(37.5 \%)$ & 0.139 \\
\hline Waist circumference, $\mathrm{sm}(\mathrm{M} \pm \sigma)$ & $102.9 \pm 9.0$ & $100.5 \pm 9.9$ & 0.110 \\
\hline Waist circumference $\geq 94 \mathrm{sm}, \mathrm{n}(\%)$ & $133(81.1 \%)$ & $34(70.8 \%)$ & 0.159 \\
\hline $\mathrm{AH}, \mathrm{n}(\%)$ & $140(85.4 \%)$ & $36(75.0 \%)$ & 0.124 \\
\hline SBP, $\mathrm{mm} \mathrm{Hg}(\mathrm{M} \pm \sigma)$ & $138.4 \pm 15.5$ & $134.7 \pm 12.5$ & 0.261 \\
\hline DBP, $\mathrm{mm} \mathrm{Hg} .(\mathrm{M} \pm \sigma)$ & $86.9 \pm 10.1$ & $85.6 \pm 10.2$ & 0.592 \\
\hline Smoking, $\mathrm{n}(\%)$ & $67(40.9 \%)$ & $15(31.3 \%)$ & 0.243 \\
\hline
\end{tabular}

Table II. Frequency of detection of phospholipid antibodies IgG class in men with stable CHD with postinfarction cardiosclerosis

\begin{tabular}{|c|c|c|c|c|c|c|c|}
\hline \multirow{3}{*}{ Group } & \multicolumn{7}{|c|}{ Frequency of IgG class antibody levels, $n(\%)$} \\
\hline & \multirow[b]{2}{*}{ Normal } & \multicolumn{3}{|c|}{ Low-positive } & \multicolumn{3}{|c|}{ Medium-positive } \\
\hline & & aPL & $\begin{array}{l}\text { anti- } \beta 2- \\
\text { GP } 1\end{array}$ & $\begin{array}{c}\text { aPL + anti- } \beta 2- \\
\text { GP } 1 \\
\end{array}$ & aPL & $\begin{array}{c}\text { anti- } \beta 2- \\
\text { GP } 1 \\
\end{array}$ & $\begin{array}{c}\text { aPL + anti- } \beta 2- \\
\text { GP } 1 \\
\end{array}$ \\
\hline Control, $n=48$ & $\begin{array}{c}34 \\
(70.8 \%) \\
\end{array}$ & $\begin{array}{c}6 \\
(12.5 \%) \\
\end{array}$ & $\begin{array}{c}4 \\
(8.3 \%) \\
\end{array}$ & $\begin{array}{c}2 \\
(4.2 \%) \\
\end{array}$ & $\begin{array}{c}1 \\
(2.1 \%) \\
\end{array}$ & $\begin{array}{c}1 \\
(2.1 \%) \\
\end{array}$ & $\begin{array}{c}0 \\
(0.0 \%) \\
\end{array}$ \\
\hline $\begin{array}{c}\text { Patients with CHD, } \\
n=164\end{array}$ & $71(43.3 \%)$ & $\begin{array}{c}7 \\
(4.3 \%) \\
\end{array}$ & $\begin{array}{c}9 \\
(5.5 \%) \\
\end{array}$ & $\begin{array}{c}42 \\
(25.6 \%) \\
\end{array}$ & $11^{*}(6.7 \%)$ & $\begin{array}{c}13^{*} \\
(7.9 \%)\end{array}$ & $\begin{array}{c}11 \\
(6.7 \%)\end{array}$ \\
\hline $\mathrm{p}$ & $<0.001$ & 0.078 & 0.496 & $<0.001$ & 0.305 & 0.199 & 0.073 \\
\hline
\end{tabular}

Note. ${ }^{*}$ - medium-positive levels of one type of antibodies were combined with low-positive levels of another type of antibodies.

Table III. Phospholipid antibody levels in men with stable CHD disease with postinfarction cardiosclerosis

\begin{tabular}{|c|c|c|c|c|}
\hline \multirow{2}{*}{ Group } & \multicolumn{2}{|c|}{ Total aPL, U / ml $(\mathrm{M} \pm \sigma)$} & \multicolumn{2}{|c|}{ Anti- $\beta 2-G P 1, U / m l(M \pm \sigma)$} \\
\hline & $\lg G$ & $\lg M$ & $\lg G$ & $\lg M$ \\
\hline Control, $n=48$ & $6.56 \pm 3.67$ & $3.38 \pm 2.26$ & $6.70 \pm 3.67$ & $3.80 \pm 2.91$ \\
\hline Patients with $\mathrm{CHD}, \mathrm{n}=164$ & $11.5 \pm 5.89$ & $6.14 \pm 4.07$ & $12.7 \pm 6.74$ & $6.72 \pm 3.93$ \\
\hline $\mathrm{p}$ & $<0.001$ & $<0.001$ & $<0.001$ & $<0.001$ \\
\hline
\end{tabular}

postinfarction cardiosclerosis, at the age of $53.0 \pm 9.14$ years and total disease duration $42.0[14 ; 99]$ months were examined. All patients were treated at the cardiology and polyclinic departments of Vinnytsia Regional Clinical Hospital named after Pirogov within 2013-2018. The study was conducted in compliance with bioethic norms according to the Helsinki Declaration "Ethical Principles for Medical Research Involving Human Subjects" with subsequent revisions, European Convention of Human Rights and Biomedicine.

The diagnosis of stable $\mathrm{CHD}$ was established according to the recommendations of the AHA / ACC (2014) and ESC (2013). Postinfarction cardiosclerosis was verified on the basis of examination of relevant medical records and the results of instrumental studies. The criteria for inclusion of patients in the study were as follows: male; age > 25 years; verified postinfarction cardiosclerosis; duration of the disease from 3 months or more after the last MI; patient's consent to participate in the study.

The study involved men with postinfarction cardiosclerosis. Exclusion criteria were the following: female, acute coronary syndrome, uncontrolled arterial hypertension
(CBP $\geq 180 \mathrm{~mm} \mathrm{Hg}, \mathrm{DBP} \geq 100 \mathrm{~mm} \mathrm{Hg}$ ), hemodynamically unstable arrhythmias, type 1 and 2 diabetes mellitus with decompensated conditions. The study included 123 (75\%) patients who underwent Q-MI and 41 (25\%) patients who underwent non-Q-MI, including 17 (10.4\%) patients who had recurrent MI. Comorbid conditions were found in $143(87.2 \%)$ patients, the most common being arterial hypertension (AH) (85.4\%) and abdominal obesity (50.6\%). The control group consisted of 48 men aged $52.1 \pm 8.69$ years and corresponded to the main group by clinical and demographic parameters (Table I).

Blood for the studies was obtained under standard conditions, in the morning on an empty stomach after a night of fasting. The serum was stored in eppendorf microtubes at $-20^{\circ} \mathrm{C}$ until the study. The determination of total aPL (to cardiolipin, phosphatidylserine, phosphatidylinositol) IgG and IgM was performed by ELISA using the Anti-Phospholipid Screen IgG / IgM kit (Orgentec Diagnostika GmbH, Germany). The results were interpreted as follows: negative result (normal level) $-\mathrm{aPL}<10 \mathrm{U} / \mathrm{ml}$, positive result $-\geq 10 \mathrm{U} /$ $\mathrm{ml}$. aPL levels above $40 \mathrm{U} / \mathrm{ml}$ were considered high-positive, 20 - $40 \mathrm{U} / \mathrm{ml}$ - medium-positive, 10 - $20 \mathrm{U} / \mathrm{ml}$ - low-posi- 
Table IV. Levels of antibodies to neutrophilic proteinase-3 / myeloperoxidase (anti-PR3 / MP0) lgG class in men with stable CHD with postinfarction cardiosclerosis

\begin{tabular}{cccc}
\hline \multirow{2}{*}{ Group } & $\begin{array}{c}\text { Anti-PR3 / } \mathbf{M P O} \text { IgG, } \mathbf{~ / ~} \\
\mathbf{m l}(\mathbf{M} \pm \boldsymbol{\sigma})\end{array}$ & \multicolumn{2}{c}{ Frequency level anti-PR3/MPO, $\mathbf{n}(\%)$} \\
\cline { 3 - 4 } & $1.81 \pm 1.51$ & Negative & Low-positive \\
\hline Control, $\mathrm{n}=48$ & $3.43 \pm 2.84^{* * *}$ & $48(100 \%)$ & $0(0.0 \%)$ \\
\hline Patients with CHD, $\mathrm{n}=164$ & $153(93.3 \%)$ & $11(6.7 \%)$
\end{tabular}

Including those depending on antibodies levels to phospholipid IgG class

\begin{tabular}{cccc}
\hline Group 1, $\mathrm{n}=71$ & $2.78 \pm 1.80^{*}$ & $70(98.6 \%)$ & $1(1.4 \%)$ \\
\hline Group 2, $\mathrm{n}=58$ & $3.39 \pm 3.06^{* *}$ & $54(93.1 \%)$ & $4(6.9 \%)$ \\
\hline Group 3, $\mathrm{n}=24$ & $4.76 \pm 3.56^{* * *} \#$ & $20(83.3 \%)$ & $4(16.7 \%)^{*} \#$ \\
\hline Group 4, $\mathrm{n}=11$ & $4.91 \pm 4.05^{* * *} \#$ & $9(81.8 \%)$ & $2(18.2 \%)^{*} \#$ \\
\hline
\end{tabular}

Notes: group 1 - normal levels of aPL and anti- $\beta 2-G P 1$; group 2 - low-positive levels of aPL and/or anti- $\beta 2-G P 1$; group 3 - medium-positive levels of aPL or anti- $\beta 2-G P 1$; group $4-$ medium-positive levels of aPL + anti- $\beta 2-G P 1$.

${ }^{*}-p<0.05,{ }^{* *}-p<0.01,{ }^{* * *}-p<0.001$ compared to control group;

$\#-p<0.05$ - compared to group 1 .

Table V. Levels of $\mathrm{lg} G$ autoantibodies in patients with CHD with postinfarction cardiosclerosis depending on clinical and demographic features

\begin{tabular}{|c|c|c|c|c|}
\hline \multirow{2}{*}{\multicolumn{2}{|c|}{ Feature }} & \multicolumn{3}{|c|}{ Levels lgG, $\mathrm{U} / \mathrm{ml}(\mathrm{M} \pm \sigma)$} \\
\hline & & aPL & anti- $\beta 2-G P 1$ & anti-PR3/MPO \\
\hline \multirow{2}{*}{$\begin{array}{l}\text { Age at which the 1st } \\
\text { Ml occurred }\end{array}$} & $<44$ years $(n=41)$ & $16.6 \pm 6.10$ & $18.0 \pm 7.10$ & $3.46 \pm 2.48$ \\
\hline & $\geq 44$ years $(n=123)$ & $9.86 \pm 4.77^{* *}$ & $11.0 \pm 5.65^{* *}$ & $3.42 \pm 2.96$ \\
\hline \multirow{2}{*}{$\begin{array}{l}\text { Duration of the } \\
\text { disease }\end{array}$} & $\leq 5$ years $(n=107)$ & $11.7 \pm 5.93$ & $13.4 \pm 7.02$ & $3.34 \pm 2.71$ \\
\hline & $>5$ years $(n=57)$ & $12.6 \pm 7.15$ & $13.1 \pm 7.84$ & $3.99 \pm 3.47$ \\
\hline \multirow{2}{*}{ Variant of the 1st MI } & Q-IM $(n=123)$ & $12.0 \pm 5.51$ & $13.6 \pm 6.46$ & $3.39 \pm 2.52$ \\
\hline & Not Q-IM $(n=41)$ & $9.75 \pm 5.81^{*}$ & $10.2 \pm 6.85^{*}$ & $3.48 \pm 3.40$ \\
\hline \multirow{2}{*}{ Number of MI } & Single IM $(n=147)$ & $10.9 \pm 5.22$ & $12.0 \pm 5.68$ & $3.35 \pm 2.65$ \\
\hline & Recurrent IM ( $n=17)$ & $17.1 \pm 8.32^{*}$ & $19.2 \pm 10.9^{*}$ & $4.31 \pm 4.17$ \\
\hline \multirow{2}{*}{$\begin{array}{c}\text { Comorbid } \\
\text { hypertension }\end{array}$} & CHD without hypertension $(n=24)$ & $11.8 \pm 5.84$ & $12.1 \pm 5.07$ & $2.99 \pm 1.73$ \\
\hline & CHD with hypertension $(n=140)$ & $11.6 \pm 6.16$ & $12.9 \pm 7.05$ & $3.51 \pm 2.98$ \\
\hline \multirow{2}{*}{ Vascular comorbidity } & without CVD and livedo reticularis $(n=147)$ & $10.8 \pm 5.43$ & $12.0 \pm 6.31$ & $2.81 \pm 1.70$ \\
\hline & with CVD + livedo reticularis $(n=17)$ & $18.6 \pm 7.40^{* * *}$ & $19.9 \pm 6.96^{* * *}$ & $8.78 \pm 4.64^{* *}$ \\
\hline \multirow{2}{*}{ Body mass index } & $<30 \mathrm{~kg} / \mathrm{m} 2(\mathrm{n}=81)$ & $11.4 \pm 5.95$ & $12.2 \pm 5.86$ & $3.18 \pm 2.57$ \\
\hline & $\geq 30 \mathrm{~kg} / \mathrm{m} 2(\mathrm{n}=83)$ & $11.9 \pm 5.84$ & $13.3 \pm 7.51$ & $3.67 \pm 3.07$ \\
\hline
\end{tabular}

Notes. ${ }^{*}-p<0.05,{ }^{* *}-p<0.01,{ }^{* * *}-p<0.001$ compared to control group

Table VI. Odds ratio for MI in men with CHD with postinfarction cardiosclerosis depending on the laboratory components of APS

\begin{tabular}{|c|c|c|c|c|}
\hline \multirow{2}{*}{ Levels of aPL IgG and anti- $\beta 2-G P 1$ lgG } & \multicolumn{2}{|c|}{ Odds ratio, OR $(95 \% \mathrm{CI})$} & \multirow{2}{*}{ p1 } & \multirow{2}{*}{ p2 } \\
\hline & Q-MI & Recurrent MI & & \\
\hline Negative & 1 & 1 & - & - \\
\hline Positive & $2.58(1.26-5.28)$ & $2.52(0.83-7,67)$ & 0.010 & 0.067 \\
\hline \multicolumn{5}{|l|}{ Including: } \\
\hline Medium-positive & $2.63(0.98-7.18)$ & $4.64(1.36-15.8)$ & 0.059 & 0.018 \\
\hline Low-positive & $2.53(1.11-5.77)$ & $1.54(0.66-5.64)$ & 0.028 & 0.730 \\
\hline
\end{tabular}

Notes. p1 - authenticity about «1st Q-MI »; p2 - «recurrent Ml».

tive. The levels of antibodies to anti- $\beta 2-$ GP 1 of IgG and IgM were determined by the Aeskulisa $\beta 2$-Glyco-GM kit (AESKU diagnostics, Germany, lot 18200). The results were interpreted as follows: negative result (normal level) $-<12 \mathrm{U} / \mathrm{ml}$, low-positive - 12 - $18 \mathrm{U} / \mathrm{ml}$, positive - > $18 \mathrm{U} / \mathrm{ml}$, including medium-positive - 18 - $40 \mathrm{U} / \mathrm{ml}$, high-positive - above 40 $\mathrm{U} / \mathrm{ml}$. The verification of clinical and laboratory components of APS was performed according to the diagnostic 
criteria of Sapporo (2006) [13] and the latest EULAR-2019 guidelines [14]. Statistical processing was performed using SPSS Statistics 22.0. Student's t-test was used to estimate the difference between groups in the normal distribution and Mann-Whitney U-test was used for the distribution which is different from normal. The normality of the distribution was checked by Kolmogorov-Smirnov and Shapiro-Wilk criteria. Pearson correlation analysis was used to determine relationships between indicators, using Fisher's exact method when comparing the frequency of changes. The odds ratio (OR), confidence intervals $(95 \% \mathrm{CI})$ were evaluated. The difference at $\mathrm{p}<0.05$ was considered significant.

\section{RESULTS}

It was found (Table II) that negative results on both $\mathrm{IgG}$ antibodies (aPL and anti- $\beta 2-\mathrm{GP} 1$ ) in the control group were found to be 1.63 times more frequent than in patients with CHD ( $\mathrm{p}<0.001)$. Low positive levels of one type of antibody were found in $20.8 \%$ of the control group and in $9.8 \%$ of patients with CHD ( $<<0.05)$. The combination of low-positive levels of aPL + anti- $\beta 2$-GP 1 was found in $25.6 \%$ of patients with $\mathrm{CHD}$, which was 6.1 times higher than in the control group. In patients with $\mathrm{CHD}$, the presence of medium-positive levels of one of the antibodies (aPL or anti- $\beta 2-\mathrm{GP} 1$ ) was combined with the presence of low-positive levels of another type of anti- $\beta 2$-GP 1 antibody, and in $6.7 \%$ of patients the medium-positive levels of both antibodies were detected simultaneously. In the control group, low-positive aPL and anti- $\beta 2$-GP 1 IgM levels were detected in $3(6.2 \%)$ and $4(8.3 \%)$ individuals. Among patients with $\mathrm{CHD}$, low-positive aPL and anti- $\beta 2$ GP 1 IgM levels were detected in 12 (7.3\%) and $15(9.1 \%)$ individuals, with medium-positive levels in $7(4.3 \%)$ and $5(3,0 \%)$ of individuals, respectively, and differences in control group were not statistically significant. Analysis of the absolute values of aPL and anti- $\beta 2-\mathrm{GP} 1 \mathrm{IgG}$ and IgM showed (Table III) that in patients with CHD these indicators are significantly higher $(1.7-1.8$ times, $\mathrm{p}<0.001)$ than in the control group. 17 (10.4\%) patients with CHD, who were detected with positive levels of aPL and anti$\beta 2-G P 1 \operatorname{IgG}$ and IgM, had had a history of non-coronary vascular manifestations of probable APS, 13 (7.9\%) had experienced an ischemic stroke or transient stroke attack, and $7(4.3 \%)$ people had had livedo reticularis including 3 of them with the previous stroke.

Among patients with CHD, 11 (6.7\%) individuals with low-positive levels of IgG (Table IV) anti-PR3 / MPO were detected, while in the control group 100\% of individuals showed negative levels of these antibodies $(p=0.073)$. Positive anti-PR3 / MPO levels were more commonly found in patients with medium-positive aPL and anti- $\beta 2-\mathrm{GP} 1$ IgGlevels than in patients with negative and low antibody phospholipid levels. On average, the level of anti-PR3 / MPO IgG in patients with CHD significantly exceeded the control group value (1.8 times), and these differences were amplified with increasing levels of antibodies to phospholipids.
The analysis of the levels of aPL, anti- $\beta 2-\mathrm{GP} 1$ and anti-PR3 / MPO IgG class in patients with CHD, depending on clinical and demographic parameters revealed certain features (Table V). So, significantly higher levels of aPL and anti- $\beta 2-\mathrm{GP} 1 \mathrm{IgG}$ were found in patients with $\mathrm{CHD}$ who underwent their first MI under 44 years (1.68 and 1.63 times respectively), in patients with Q-MI (1,24 and 1.33 times respectively), recurrent MI (1.56 and 1.60 times respectively), in the presence of non-coronary vascular manifestations (1.72 and 1.66 times respectively). Differences in the level of aPL and anti- $\beta 2-G P 1$ in patients with CHD, depending on the duration of the disease, hypertension and body mass index have not been established. Patients with cerebrovascular disease (CVD), such as stroke or transient ischemic attacks and livedo reticularis, were found to have significantly higher levels of anti-PR3 / MPO IgG (3.12 times) than patients without vascular manifestations. There were no other clinical manifestations for differences in anti-PR3 / MPO IgG levels in patients with CHD.

Thus, in men with postinfarction cardiosclerosis, IgG positivity according to total aPL and anti- $\beta 2-\mathrm{GP} 1$ is associated with a higher incidence of Q-MI (OR 2.58, 95\% CI $1.26-5.28, \mathrm{p}=0.01$ ) and in the presence of medium-positive levels of these autoantibodies with recurrent $\mathrm{MI}$ (OR 4.64, 95\% CI 1.36-15.8, $\mathrm{p}=0.018$ ). (Table VI).

\section{DISCUSSION}

According to the results of this study, in the primary testing of 164 men with postinfarction cardiosclerosis, the overall frequency of aPL positivity was $56.7 \%$, including two antibodies (aPL + anti- $\beta 2-G P 1)-33.5 \%$. There is evidence that in individuals with triple aPL positivity during primary testing (lupus anticoagulant + cardiolipin antibodies (aCL) + anti- $\beta 2$-GP 1 ), this aPL profile is confirmed after 12 weeks in $98 \%$ of cases, in individuals with double aPL- positivity in $88 \%$ of cases, and in individuals with isolated aPL positivity in only $40 \%$ of cases [15]. The results of long-term prospective studies on asymptomatic carriers of laboratory markers of APS indicate a high risk of thrombotic events in the case of double or triple positivity for aPL, while positivity for one type of antibodies is not associated with an increased risk of thrombosis [16]. A meta-analysis of 11 studies with a total of 2425 patients with $\mathrm{CHD}$ (283 individuals with IgG positive aCL) showed an increase in the relative risk of major cardiac events in 12 and 24 months (RR 2.17 and 2,11 respectively). [5]. In IgG aCL-positive patients with "juvenile" CHD (younger than 50 years), the relative risk of recurrent major cardiac events after 12 and 24 months increased more significantly (3.21 and 3.24, respectively) [5].

\section{CONCLUSIONS}

Thus, in men with postinfarction cardiosclerosis, double positivity for total aPL and IgG anti- $\beta 2-\mathrm{GP} 1$ is closely associated with the early manifestation of $\mathrm{CHD}$ (at the age of 44 years), Q-MI and recurrent MI. Besides, in the case 
of double positivity to aPL and anti- $\beta 2-\mathrm{GP} 1 \mathrm{IgG}$, there is a tendency to increase the levels of anti-PR3 / MPO IgG class, which is associated with vascular pathology (strokes, livedo reticularis). Therefore, the persistence of the production of aPL and antineutrophil antibodies forms an unfavorable pathogenetic pattern that can significantly modify the course of CHD in men.

\section{REFERENCES}

1. Artenjak A, Lakota K, Frank M et al. Antiphospholipid antibodies as nontraditional risk factors in atherosclerosis based cardiovascular diseases without overt autoimmunity. A critical updated review. Autoimmun. Rev. 2012;11(12):873-882. doi: 10.1016/j.autrev.2012.03.002.

2. Kolitz T, Shiber S, Sharabi I et al. Cardiac Manifestations of Antiphospholipid Syndrome With Focus on Its Primary Form. Front Immunol. 2019;941:1-11. doi:10.3389/fimmu.2019.00941.

3. Stepien K, Nowak K, Wypasek E et al. High prevalence of inherited thrombophilia and antiphospholipid syndrome in myocardial infarction with non-obstructive coronary arteries: Comparison with cryptogenic stroke. Int J Cardiol. 2019; 290:1-6. doi: 10.1016/j.ijcard.2019.05.037.

4. Schreiber K, Sciascia S, de Groot PG et al. Antiphospholipid syndrome. Nat Rev Dis Primers. 2018;4(1):1-20. doi: 10.1038/nrdp.2017.103.

5. Pastori D, Bucci T, Triggiani M et al. Immunoglobulin G (IgG) anticardiolipin antibodies and recurrent cardiovascular events. A systematic review and Bayesian meta-regression analysis. Autoimmun Rev. 2019;18(5):519-525. doi: 10.1016/j.autrev.2019.03.005.

6. Morton KE, Gavaghan TP, Krilis SA et al. Coronary artery bypass graft failure--an autoimmune phenomenon? The Lancet. 1986;328(8520):1353-1357.

7. Saifutdinov R.R., Bogoyavlensky V.F., Gorina M.V. etc. Antitela k phospholipidam u pasientov, perenesshih OIM i so stabilnoy stenokardiey, ih svyaz s nekotorimi pokazatelyami krovi [Antibodies to phospholpids in patients after AMI and with stable angina pectoris, their relationship with some indicators of blood tests]. Newsletter of NWSMU. 2009;2/1:70-76. (in Russian).

8. Ramadan MM, Tachikawa H, Kodama M et al.Y. A pilot-controlled study of myeloperoxidase-specific anti-neutrophil cytoplasmic autoantibody (MPO-ANCA) in the coronary circulation. Int J Cardiol. 2008;128(1): 114-116.

9. Shah AS, Din JN, Payne JR et al. Coronary angiitis and cardiac arrest in antineutrophil cytoplasmic-antibody associated systemic vasculitis. Circulation. 2011;123(6):230-231. doi: 10.1161/ CIRCULATIONAHA.110.981936.

10. Suppiah R, Judge A, Batra R et al. A model to predict cardiovascular events in patients with newly diagnosed Wegener's granulomatosis and microscopic polyangiitis. Arthritis Care Res. 2011;63(4):588-596. doi:10.1002/acr.20433.

11. Granger DN, Rodrigues SF, Yildirim A et al. Microvascular responses to cardiovascular risk factors. Microcirculation. 2010;17(3):192-205. doi:10.1111/j.1549-8719.2009.00015.x
12. Yoo J, Ahn SS, Jung SM et al. Persistent antiphospholipid antibodies are associated with thrombotic events in ANCA-associated vasculitis: A retrospective monocentric study. J Nefrol. 2019;39(4), 395-401. doi. org/10.1016/j.nefro.2018.10.014.

13. Miyakis S, Lockshin MD, Atsumi T et al. International consensus statement on an update of the classification criteria for definite antiphospholipid syndrome (APS). J Thromb Haemost. 2006;4(2):295306. doi.org/10.1111/j.1538-7836.2006.01753.x

14. Tektonidou MG, Andreoli L, Limper M et al. EULAR recommendations for the management of antiphospholipid syndrome in adults. Annals of the Rheumatic Diseases. 2019;78(10):1296-1304.

15. PengoV, RuffattiA, Del RossT etal.Confirmation of initial antiphospholipid antibody positivity depends on the antiphospholipid antibody profile. J Thromb Haemost. 2013;11(8):1527-1531. doi: 10.1111/jth.12264.

16. Mustonen $\mathrm{P}$, Lehtonen $\mathrm{KV}$, Javela $\mathrm{K}$ et al. Persistent antiphospholipid antibody (aPL) in asymptomatic carriers as a risk factor for future thrombotic events: a nationwide prospective study. Lupus. 2014;23(14):1468-1476. doi: 10.1177/0961203314545410.

Topic: "Metabolic risk factors, cardiovascular remodeling and functional status of kidneys in patients with cardiovascular pathology. Possibilities of pharmacological correction"

\section{ORCID and contributionship:}

Marina S. Nazarova - 0000-0001-6981-9522 A, B, C, D, F

Mykola A. Stanislavchuk - 0000-0001-8160-8189 E, F

Liudmyla V. Burdeina - 0000-0001-7450-7777 D, E

Nataliia V. Zaichko - 0000-0003-1889-6151 ${ }^{E}$

\section{Conflict of interest:}

The Authors declare no conflict of interest.

\section{CORRESPONDING AUTHOR Marina S. Nazarova National Pirogov Memorial Medical University Shevshenk0 5a/23 str., Vinnytsia, Ukraine, 21036 tel: +380982792057 \\ e-mail:mburdeyna@gmail.com}

Received: 17.01 .2020

Accepted: 05.03.2020

A - Work concept and design, B - Data collection and analysis, C - Responsibility for statistical analysis, D-Writing the article, $\mathbf{E}$-Critical review, $\mathbf{F}$ - Final approval of the article 